\title{
Biosynthesis, Characterization and Antibacterial Application of Novel Silver Nanoparticles against Drug Resistant Pathogenic Klebsiella pneumoniae and Salmonella Enteritidis
}

\author{
Md. Amdadul Huq ${ }^{1, *}$ and Shahina Akter ${ }^{2, *}$ \\ 1 Department of Food and Nutrition, College of Biotechnology and Natural Resource, Chung-Ang University, \\ Anseong 17546, Korea \\ 2 Department of Food Science and Biotechnology, Gachon University, Seongnam 461-701, Korea \\ * Correspondence: amdadbge@gmail.com or amdadbge100@cau.ac.kr (M.A.H.); shahina@gachon.ac.kr (S.A.); \\ Tel.: +82-031-670-4568 (M.A.H.)
}

check for updates

Citation: Huq, M.A.; Akter, S. Biosynthesis, Characterization and Antibacterial Application of Novel Silver Nanoparticles against Drug Resistant Pathogenic Klebsiella pneumoniae and Salmonella Enteritidis. Molecules 2021, 26, 5996. https:// doi.org/10.3390/molecules26195996

Academic Editors: Miguel Ángel Morcillo Alonso, Jorge Rubio-Retama and Piersandro Pallavicini

Received: 21 August 2021

Accepted: 27 September 2021

Published: 2 October 2021

Publisher's Note: MDPI stays neutral with regard to jurisdictional claims in published maps and institutional affiliations.

Copyright: (c) 2021 by the authors. Licensee MDPI, Basel, Switzerland. This article is an open access article distributed under the terms and conditions of the Creative Commons Attribution (CC BY) license (https:/ / creativecommons.org/licenses/by/ $4.0 /)$.

\begin{abstract}
The present study highlights the biosynthesis of silver nanoparticles (AgNPs) using culture supernatant of Massilia sp. MAHUQ-52 as well as the antimicrobial application of synthesized AgNPs against multi-drug resistant pathogenic Klebsiella pneumoniae and Salmonella Enteritidis. Well-defined AgNPs formation occurred from the reaction mixture of cell-free supernatant and silver nitrate $\left(\mathrm{AgNO}_{3}\right)$ solution within $48 \mathrm{~h}$ of incubation. UV-visible spectroscopy analysis showed a strong peak at $435 \mathrm{~nm}$, which corresponds to the surface plasmon resonance of AgNPs. The synthesized AgNPs were characterized by FE-TEM, EDX, XRD, DLS and FT-IR. From FE-TEM analysis, it was found that most of the particles were spherical shape, and the size of synthesized nanoparticles (NPs) was 15-55 $\mathrm{nm}$. EDX spectrum revealed a strong silver signal at $3 \mathrm{keV}$. XRD analysis determined the crystalline, pure, face-centered cubic AgNPs. FT-IR analysis identified various functional molecules that may be involved with the synthesis and stabilization of AgNPs. The antimicrobial activity of Massilia sp. MAHUQ-52 mediated synthesized AgNPs was determined using the disk diffusion method against K. pneumoniae and S. Enteritidis. Biosynthesized AgNPs showed strong antimicrobial activity against both K. pneumoniae and S. Enteritidis. The MICs of synthesized AgNPs against K. pneumoniae and $S$. Enteritidis were 12.5 and $25.0 \mu \mathrm{g} / \mathrm{mL}$, respectively. The MBC of biosynthesized AgNPs against both pathogens was $50.0 \mu \mathrm{g} / \mathrm{mL}$. From FE-SEM analysis, it was found that the AgNPs-treated cells showed morphological changes with irregular and damaged cell walls that culminated in cell death.
\end{abstract}

Keywords: Massilia sp. MAHUQ-52; biosynthesis; AgNPs; K. pneumoniae; S. Enteritidis

\section{Introduction}

Various metal nanoparticles (NPs) are synthesized due to their unique properties, such as electrical, optical, biological, catalytic, and magnetic characteristics and low-cytotoxicity and enhanced permeability [1-3]. Among different metal NPs, silver nanoparticles (AgNPs) have drawn countless attention due to their various applications in different sectors as cancer therapeutics, biosensors, antibiotics, anti-inflammatory and drug delivery, etc. [4-11] Many recent studies reported that biogenic AgNPs exhibited strong antibacterial activity against different pathogenic microorganisms $[9,12,13]$. Studies also suggest that biosynthesized AgNPs have excellent anti-inflammatory and anti-cancer activities [5,6]. According to Fouda et al. [7,8], biogenic AgNPs showed strong activity in degrading various toxic chemicals. Recently, biosynthesized AgNPs have been used for food preservation, sanitization, water filtration, nanoinsecticides, nanopesticides and cosmetics, etc. [10,14,15]. Different physical and chemical methods have been applied for the synthesis of metal NPs. However, globally, it is realized that biological synthesis methods are safe, facile, and non-toxic compared to the expensive, toxic and dangerous chemical and physical processes $[7,16]$. Various destructive impacts of chemical and physical methods can be solved through the 
biosynthesis of NPs using different biological entities. Therefore, it is essential to develop a simple, cost-effective, non-toxic, and environmentally friendly approach for the facile and mass production of metal NPs using biological systems. Biological synthesis can be performed using either bacteria [17], fungi [18] or plant extracts [19,20]. Among various biological entities, bacterial-mediated synthesis of NPs is mostly preferred due to their largescale production, high growth rate and ease of handling [13,21]. Different studies showed the biosynthesis of AgNPs using bacteria including Microvirga rosea, Paenibacillus anseongensis, Novosphingobium sp., Sporosarcina koreensis DC4, Terrabacter humi, Pseudomonas sp., etc. [22-27]. Rhizosphere bacteria are considered to be useful in various sectors, such as in phytoremediation, biotransformation and biosynthesis of valuable products, to increase plant growth and productivity, etc. [22,28].

The emergence of multidrug-resistant (MDR) microorganisms due to the uncontrolled, immoderate and multiple uses of antibiotics and chemotherapeutics is a serious threat to the world population. Klebsiella pneumoniae is a Gram-negative, non-motile, facultative anaerobic, encapsulated, rod-shaped bacterium that can cause various types of healthcareassociated diseases, including pneumonia, wound or surgical site infections, bloodstream infections, and meningitis [29]. Salmonella Enteritidis is a food-borne pathogen and can cause various food-borne illnesses in humans including gastroenteritis when contaminated food is consumed. Salmonellosis is a common food-borne disease that is caused by the infection of Salmonella. Salmonella outbreaks are severe for those vulnerable people who are immunocompromised, young and old [30]. Recently, both K. pneumoniae and S. Enteritidis have shown resistance against different antibiotics $[29,30]$. The development of a new antimicrobial agent is the decisive solution for this issue. Therefore, biosynthesized AgNPs may be a promising agent to control these MDR microorganisms. This study was designed to use the culture supernatant of Massilia sp. MAHUQ-52 for the facile, non-toxic and eco-friendly synthesis of AgNPs, which were evaluated for their acceptability as an antimicrobial agent to control the multi-drug resistant pathogenic K. pneumoniae and S. Enteritidis. This is the first report for the biosynthesis of novel AgNPs using Massilia sp. MAHUQ-52 and their antimicrobial efficacy against pathogenic K. pneumoniae and S. Enteritidis.

\section{Results and Discussion}

\subsection{Identification and Characterization of AgNPs-Producing Strain MAHUQ-52}

Strain MAHUQ-52 was isolated from the rhizospheric soil of a banana plant and used for the biologically facile synthesis of AgNPs. The 16S rRNA gene sequence of strain MAHUQ-52 was $1461 \mathrm{bp}$, and the sequence was deposited in NCBI GenBank under accession number MT514500. According to the 16S rRNA gene sequence analysis using EzBioCloud server, strain MAHUQ-52 showed the highest 16s rRNA sequence similarity with Massilia aurea $\mathrm{AP} 13^{\mathrm{T}}(97.8 \%)$. The phylogenetic analysis based on the neighborjoining method revealed that strain MAHUQ-52 is grouped within the genus Massilia (Figure 1). The closest relative Massilia aurea $\mathrm{AP}^{1} 3^{\mathrm{T}}$ is reported to be a motile, strictly aerobic, nonspore-forming, Gram-negative and straight rod-shaped bacterium, which belongs to the Oxalobacteraceae family [31]. Different species of the genus Massilia have been isolated from various environments, including air, rock surface, soil, water, and ice core, etc. [32]. Pending further molecular characterization, we will refer to this strain as Massilia sp. MAHUQ-52. Strain MAHUQ-52 grows on R2A agar (best growth medium), NA and TSA, but did not grow on LB agar or MacConkey agar. Growth occurs at $10-35^{\circ} \mathrm{C}$ (optimum, $30^{\circ} \mathrm{C}$ ), at $\mathrm{pH}$ 6.0-9.0 (optimum, $\mathrm{pH} 7.0$ ) and with $0-1.0 \% \mathrm{NaCl}$ (optimum, $0 \%$ ). Strain MAHUQ-52 has been deposited in KACC (KACC 21999). 


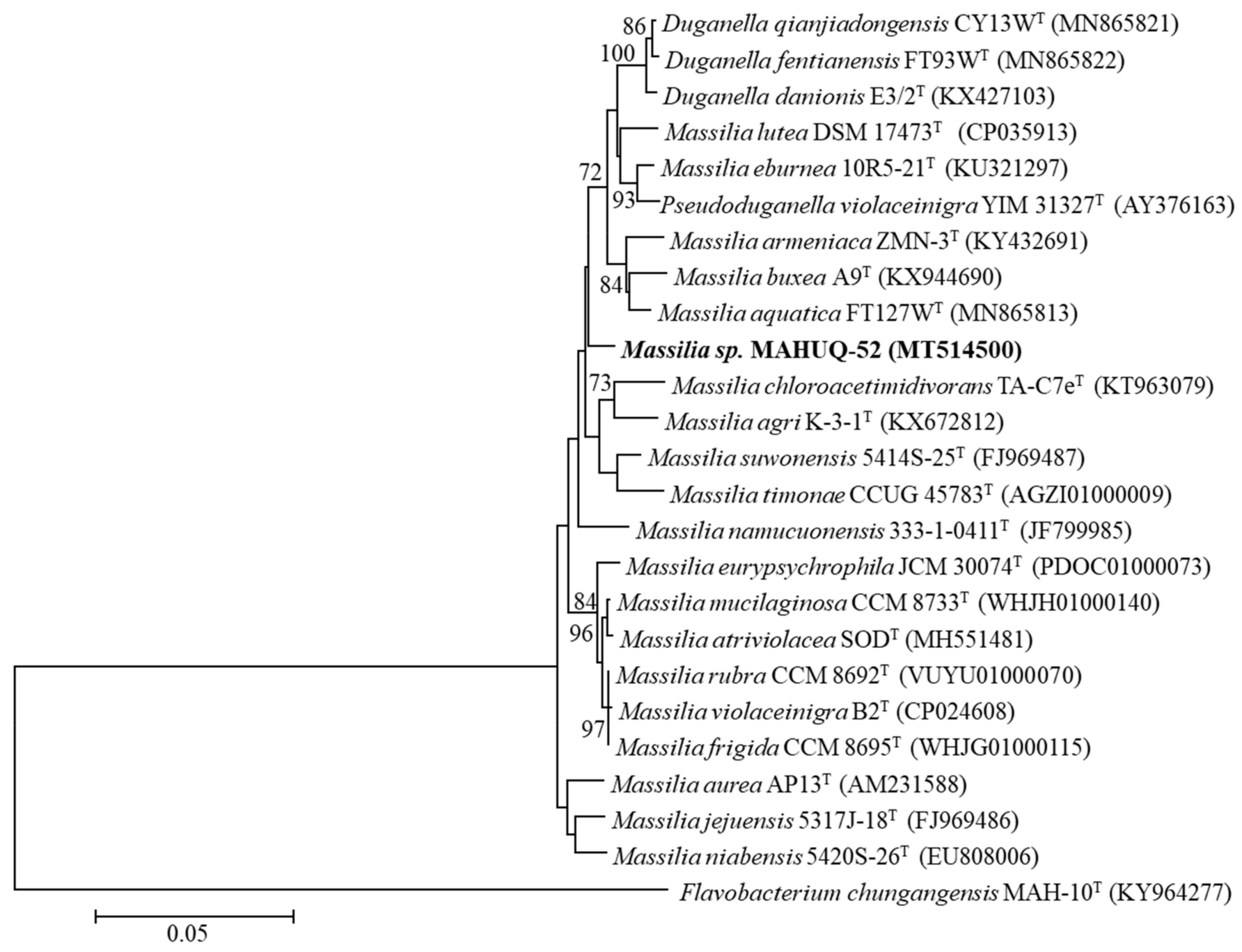

Figure 1. The neighbor-joining (NJ) tree based on 16S rRNA gene sequence analysis showing phylogenetic relationships of strain MAHUQ-52 and the related type strains. Bootstrap values more than $70 \%$ based on 1000 replications are shown at branching points. Scale bar, 0.05 substitutions per nucleotide position.

\subsection{Biosynthesis of AgNPs Using Massilia sp. MAHUQ-52}

Massilia sp. MAHUQ-52 reduced the silver ions to silver NPs. The biosynthesis of AgNPs was confirmed by changing from light yellow color to dark brown after $48 \mathrm{~h}$ of incubation with $1 \mathrm{mM}$ aqueous $\mathrm{AgNO}_{3}$ into the cell-free Massilia sp. MAHUQ-52 supernatant (Figure 2B). However, no color change was found in the control incubated under the same conditions without cell-free supernatant (Figure 2A). The formation of dark brown color depends on the surface plasmon resonance. The optimum incubation time ( $48 \mathrm{~h}$ ) for green and facile synthesis of AgNPs was examined based on UV-vis spectral analysis (Supplementary Materials Figure S1). There are two methods (extracellular and intracellular) that are available for the biosynthesis of AgNPs using bacteria. Among these two methods, the extracellular method is facile, rapid and easy compared to the intracellular method that requires complex purification steps [33]. In our present study, the facile and convenient extracellular methodology was used to synthesis the AgNPs using Massilia sp. MAHUQ-52. Our results agree with Singh et al. [34], who mentioned that when cell-free culture supernatant of Solibacillus isronensis sp. was added to $\mathrm{AgNO}_{3}$ solution and incubated for $48 \mathrm{~h}$ the color of the reaction mixtures changed from pale yellow to dark brown. Rhizosphere bacteria play vital roles in biotransformation, phytoremediation, plant nutrition, growth promotion, etc. [22,28]. Therefore, the rhizosphere bacterial strain 
Massilia sp. MAHUQ-52 was considered the most potent isolate for the biosynthesis of AgNPs due to the color changes and maximum absorption peak.

(A)

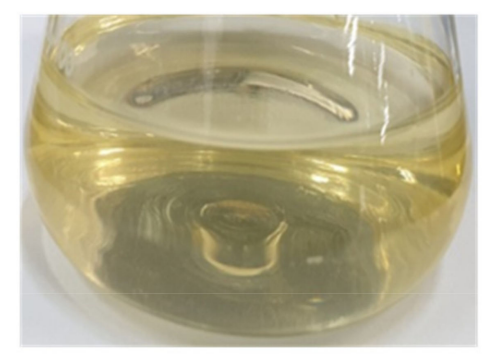

(D)

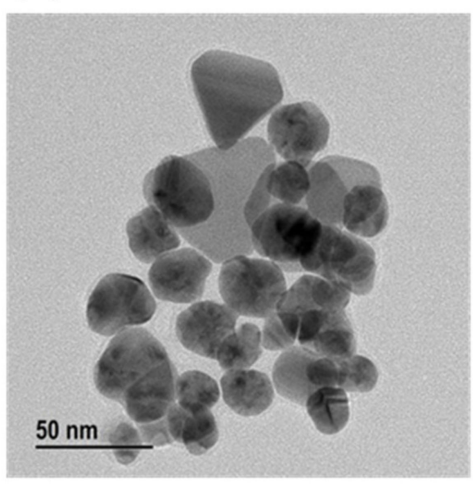

(B)

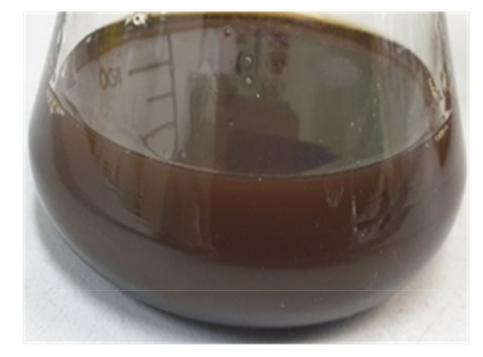

(E)

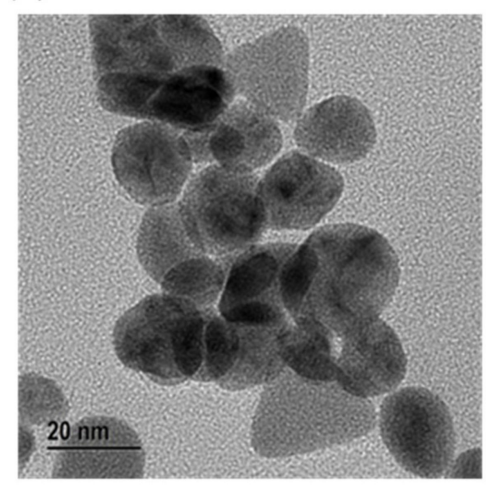

(C)

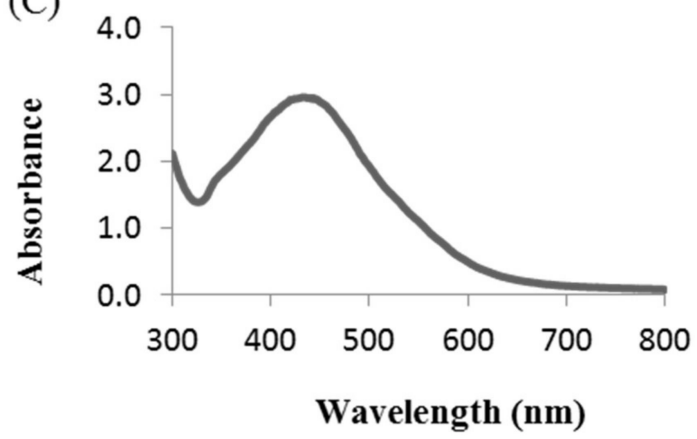

(F)

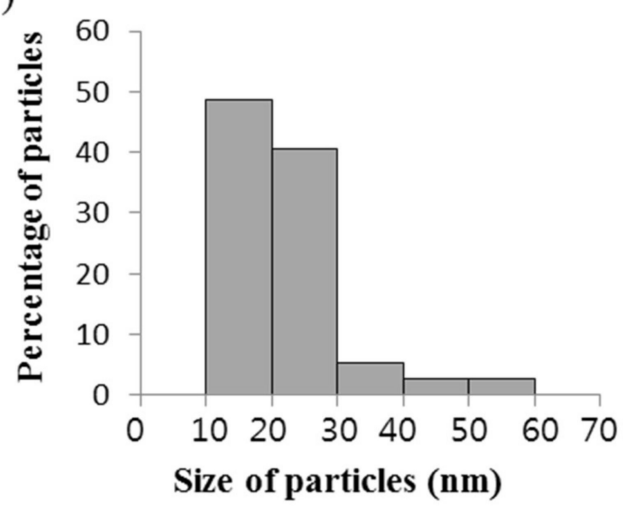

Figure 2. R2A broth with $\mathrm{AgNO}_{3}$ as control (A), Massilia sp. MAHUQ-52 mediated synthesized AgNPs (B), UV-vis spectra (C), FE-TEM images of synthesized AgNPs (D,E) and histogram of various sizes of synthesized AgNPs (F).

\subsection{Characterization of Biosynthesized AgNPs}

The synthesis of AgNPs using Massilia sp. MAHUQ-52 was confirmed by UV-visible spectrophotometry within 300-800 nm range which showed an absorption peak of $435 \mathrm{~nm}$ (Figure 2C), indicating the existence of AgNPs. Depending on nanoparticle (NP) properties, such as shape, size and capping agents, the exact location of the SPR band can vary [35]. According to Brause et al., the absorption pick is associated with NP size [36]. The SPR of different metal NPs in an aqueous solution increases to longer wavelengths by increasing the particle size. Krishnaraj et al. reported that the position and form of metal NP absorption pick are strongly dependent on the size of the particle, stabilizing molecules and the bioelectricity of media [37]. Our results agree with Akter et al. [26], who mentioned that the silver SPR band of Terrabacter humi mediated synthesized NPs occurred at $413 \mathrm{~nm}$. The morphology (shape and size) of synthesized NPs were analyzed by FE-TEM. The TEM analysis revealed the spherical shape of biosynthesized AgNPs (Figure 2D,E). The size of Massilia sp. MAHUQ-52 mediated synthesized AgNPs was in a range of $15-55 \mathrm{~nm}$. Figure $2 \mathrm{~F}$ showed the histogram of sizes of green synthesized AgNPs. The average size of green synthesized AgNPs was $23.2 \mathrm{~nm}$. A similar particle size was formed by Cedecea sp. in the range of 10-40 nm [38]. Energy dispersive X-Ray (EDX) and elementary mapping was used to investigate the purity and elemental composition of synthesized AgNPs. In the present study, EDX spectroscopy analysis was carried out for AgNPs produced by Massilia sp. MAHUQ-52 (Figure 3A-C), which ensured the presence of elemental silver based on the signals. In the EDX spectrum, the synthesized NPs showed a peak at $3 \mathrm{keV}$, which was due to the presence of silver nanocrystallites [26]. Two other peaks were also found due to the presence of copper grids (Figure 3A). The elemental mapping results of the synthesized nanoproducts reveal the maximum distribution of silver elements, suggesting that silver was the predominant element in the synthesized NPs (Figure 3B,C; Table 1). 
(A)

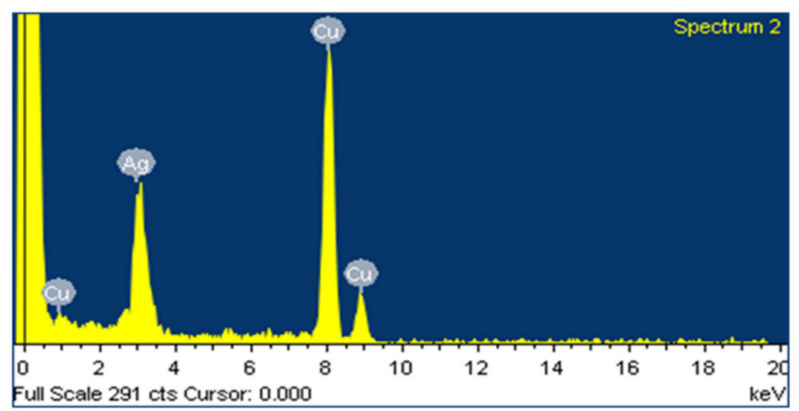

(B)

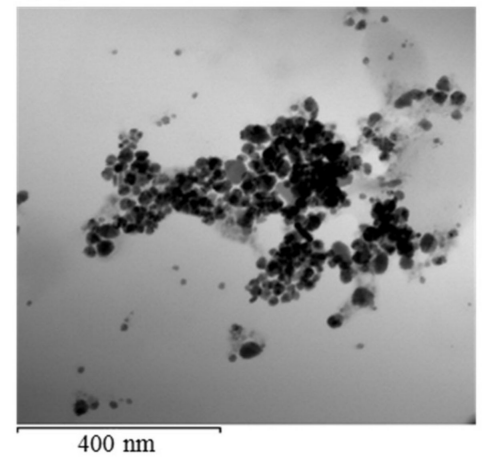

(C)

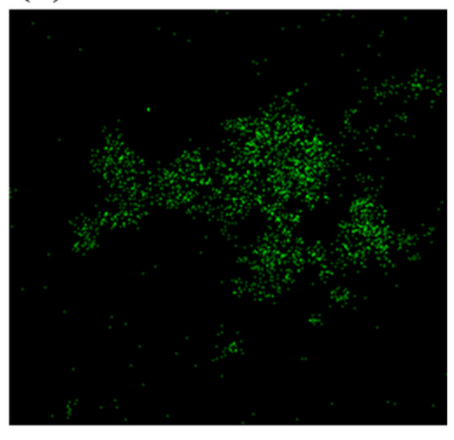

(D)

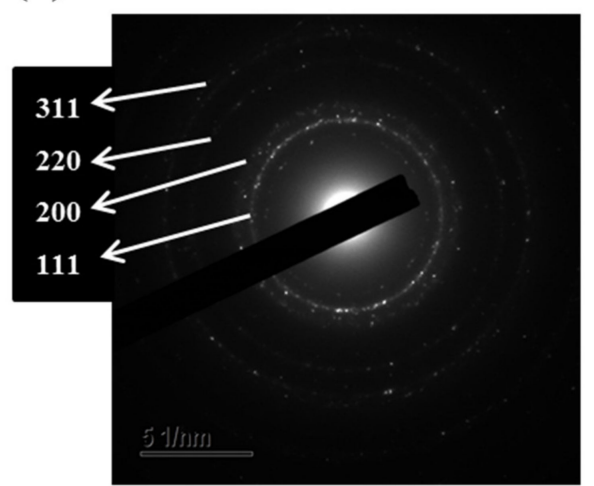

(E)

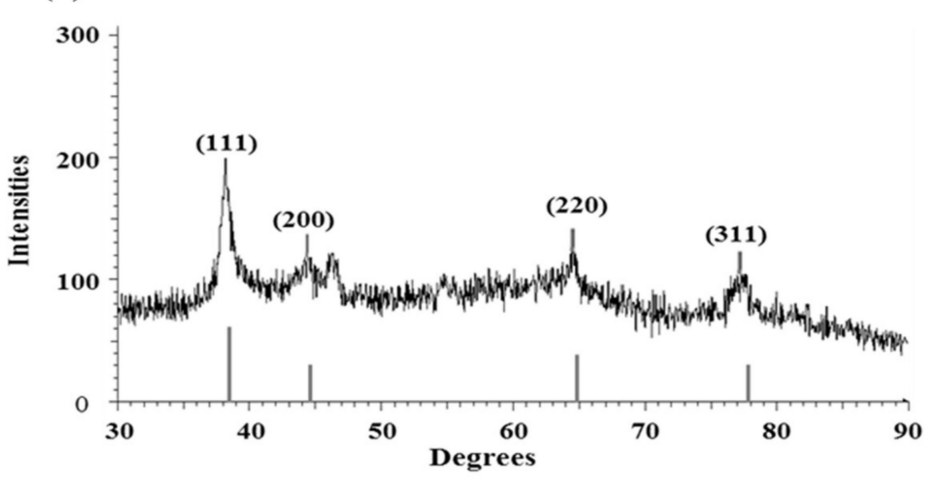

Figure 3. EDX spectrum of synthesized AgNPs (A), TEM image used for mapping (B), distribution of silver in elemental mapping (C), SAED pattern (D) and X-ray diffraction pattern (E) of Massilia sp. MAHUQ-52 mediated synthesized AgNPs.

Table 1. The number and percentage of chemical elements present in EDX spectrum of Massilia sp. MAHUQ-52 mediated synthesized AgNPs.

\begin{tabular}{ccc}
\hline Element & Weight $\%$ & Atomic\% \\
\hline Cu K & 57.40 & 69.58 \\
Ag L & 42.60 & 30.42 \\
Totals & 100.00 & 100.00 \\
\hline
\end{tabular}

The XRD pattern of synthesized NPs revealed intensive peaks throughout the twoparty scope in the range of $30-90^{\circ}$, similar to the Bragg's AgNPs reflection, which indicated the formation of AgNPs. AgNPs produced by Massilia sp. MAHUQ-52 showed distinguished XRD peaks at $38.25,44.65,64.90$ and $77.80^{\circ}$ with $2 \theta$ values (Figure $3 \mathrm{E}$ ). These peaks are corresponding to the 111, 200, 220 and 311 reflection planes of face-centered-cubic (fcc) silver, respectively. Our findings agree with Du et al. [23] and Singh et al. [27], who showed a similar XRD pattern of AgNPs synthesized by bacteria. SAED analysis showed sharp rings which indicate the crystalline nature of AgNPs and corresponding to the reflections of 111, 200, 220, and 311 (Figure 3D). Similar results were reported by Huq [4]. The DLS analysis revealed that the average particle size of the synthesized AgNPs was around $109.3 \mathrm{~nm}$, and the polydispersity index was 0.294 (Supplementary Figure S2). The zeta potential value of the aqueous AgNPs solution was $-18.4 \mathrm{mV}$ (Supplementary Figure S3). The size of biosynthesized AgNPs is different from the results found from FE-TEM analyses. This may be because DLS measures the total hydrodynamic radius of the AgNPs in solution, which includes conjugated molecules instead of particle size.

Fourier-transform infrared (FT-IR) analysis was performed to characterize the surface chemistry and identify the functional molecules involved with the biosynthesis of AgNPs by Massilia sp. MAHUQ-52. FT-IR spectrum of air-dried powder of purified AgNPs displayed the vibrational stretches at 3270.50, 2918.61, 2847.80, 2046.80, 1959.53, 1621.78, 
$1536.69,1376.40$ and $1048.71 \mathrm{~cm}^{-1}$ (Figure 4A). The vibration band at $3270.50 \mathrm{~cm}^{-1}$ can be attributed to stretching vibrations of O-H (alcohol) and / or N-H (amine). The spectral peaks at 2918.61 and $2847.80 \mathrm{~cm}^{-1}$ correspond to the $\mathrm{C}-\mathrm{H}$ group. The absorbance peaks at 2046.80 and $1959.53 \mathrm{~cm}^{-1}$ can be represented as alkyne group. Peaks found at 1621.78 and $1536.69 \mathrm{~cm}^{-1}$ can be ascribed to $\mathrm{C}=\mathrm{O}$ (ester) or $-\mathrm{C}=\mathrm{C}$ bond. The fingerprint region showed spectral peaks at 1376.40 and $1048.71 \mathrm{~cm}^{-1}$ can be attributed to $\mathrm{C}-\mathrm{H}$ bending or COOgroups and C-O (alcohol/ether) or C-N (amine) stretching, respectively. FT-IR spectrum of bacterial culture supernatant also displayed the identical vibrational stretches at 3256.21, 2931.72, 2877.00, 2021.83, 1997.98, 1592.94, 1452.79, 1395.89 and $1040.80 \mathrm{~cm}^{-1}$ (Figure 4B). The results of this study coincided with other reports $[23,27,38]$. FT-IR analysis revealed the binding of carbohydrates, proteins, and phospholipids with synthesized NPs which contributed for the stability of NPs, as well as capping and functionalizing agents.

(A)

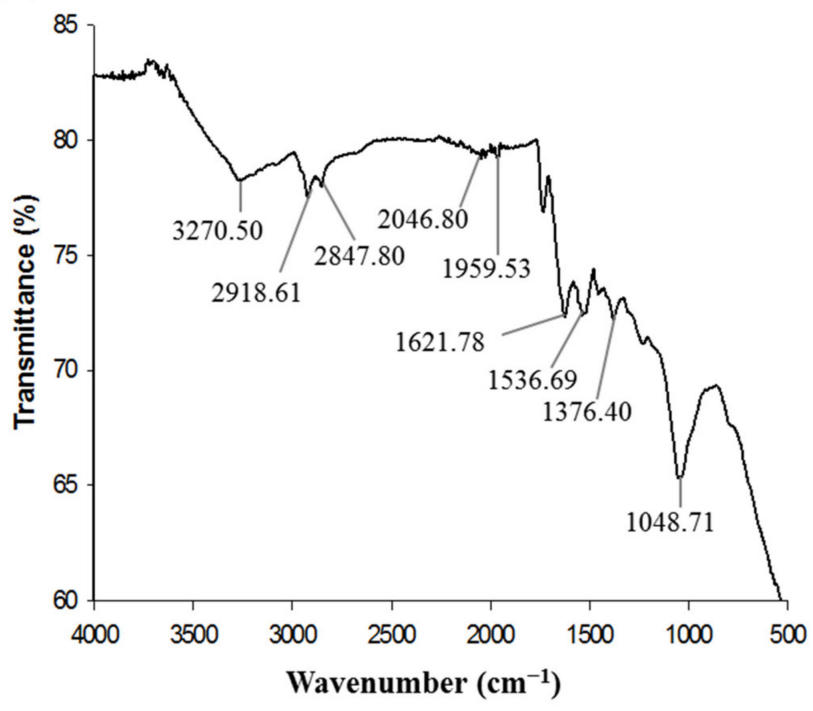

(B)

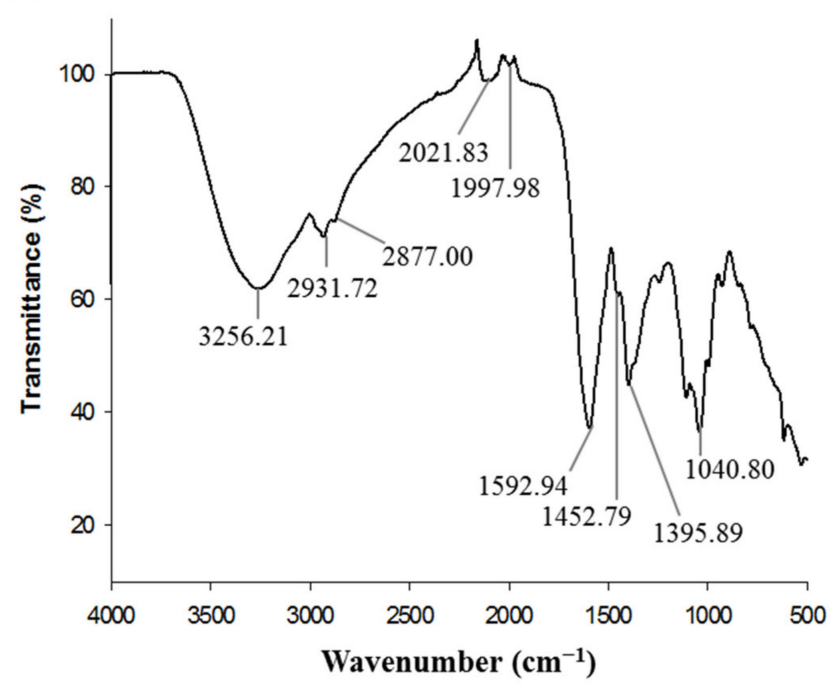

Figure 4. FT-IR spectra of Massilia sp. MAHUQ-52 mediated synthesized AgNPs (A) and bacterial culture supernatant (B).

\subsection{Antimicrobial Activity of Biosynthesized AgNPs}

NPs have a high surface-volume ratio with a small size that makes them capable to interact with microbial surfaces. The large surface area of AgNPs promotes their interaction with pathogens to perform antimicrobial activities [38]. In the present study, the inhibitory potential of Massilia sp. MAHUQ-52 mediated synthesized AgNPs against two multi-drug resistant human pathogenic bacteria K. pneumoniae and S. Enteritidis was investigated by disk diffusion assay. The potential antimicrobial properties of biosynthesized AgNPs against tested pathogens were confirmed by the formation of a clear zone of inhibition (ZOI) (Figure 5). The formation of clear ZOI ensured the complete growth inhibition of K. pneumoniae and S. Enteritidis. The diameters of ZOI are shown in Table 2. The diameters of inhibition zone of Massilia sp. MAHUQ-52 mediated synthesized AgNPs against K. pneumoniae and $S$. Enteritidis were $17.6 \pm 0.5$ and $16.8 \pm 0.9 \mathrm{~mm}$, respectively. These findings are consistent with previous studies that showed the antimicrobial activities of biosynthesized AgNPs against Bacillus cereus and Pseudomonas aeruginosa [17]. Six standard antibiotic disks, including erythromycin, vancomycin, penicillin, novobiocin, oleandomycin and lincomycin, were also used as a control to check their antibacterial efficacy. It was found that $S$. Enteritidis showed a resistant pattern against five tested antibiotics. From Figure 6, it was found that only penicillin had antibacterial efficacy against $S$. Enteritidis (Table 2). Conversely, only novobiocin showed activity against K. pneumoniae, but the other five antibiotics - erythromycin, vancomycin, penicillin, oleandomycin and lincomycin-did not show any activity against K. pneumoniae (Figure 6, Table 2). The inhibition potential of Massilia sp. MAHUQ-52 mediated synthesized AgNPs against $K$. 
pneumoniae and S. Enteritidis was significantly higher than the tested antibiotics. The inhibitory action of AgNPs against pathogens due to their small size and large surface area make it perfect to interact with the microbial cell membrane [38]. Massilia sp. MAHUQ52 mediated synthesized AgNPs can be used to overcome the resistance pattern of $K$. pneumoniae and S. Enteritidis.
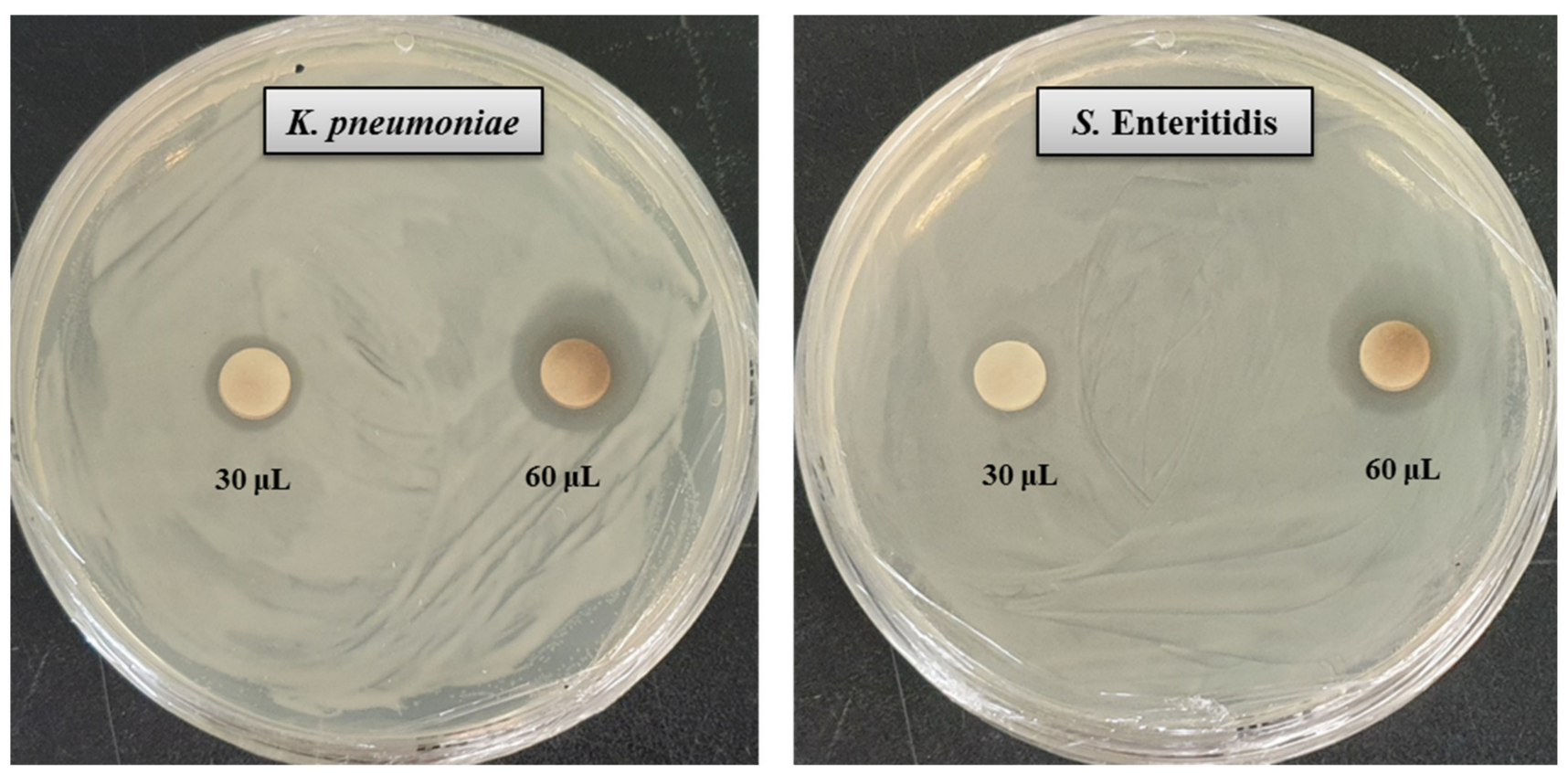

Figure 5. Zones of inhibition of biosynthesized AgNPs ( $30 \mu \mathrm{L}$ and $60 \mu \mathrm{L}$ at 1000 ppm concentrations in water) against $K$. pneumoniae and $S$. Enteritidis.
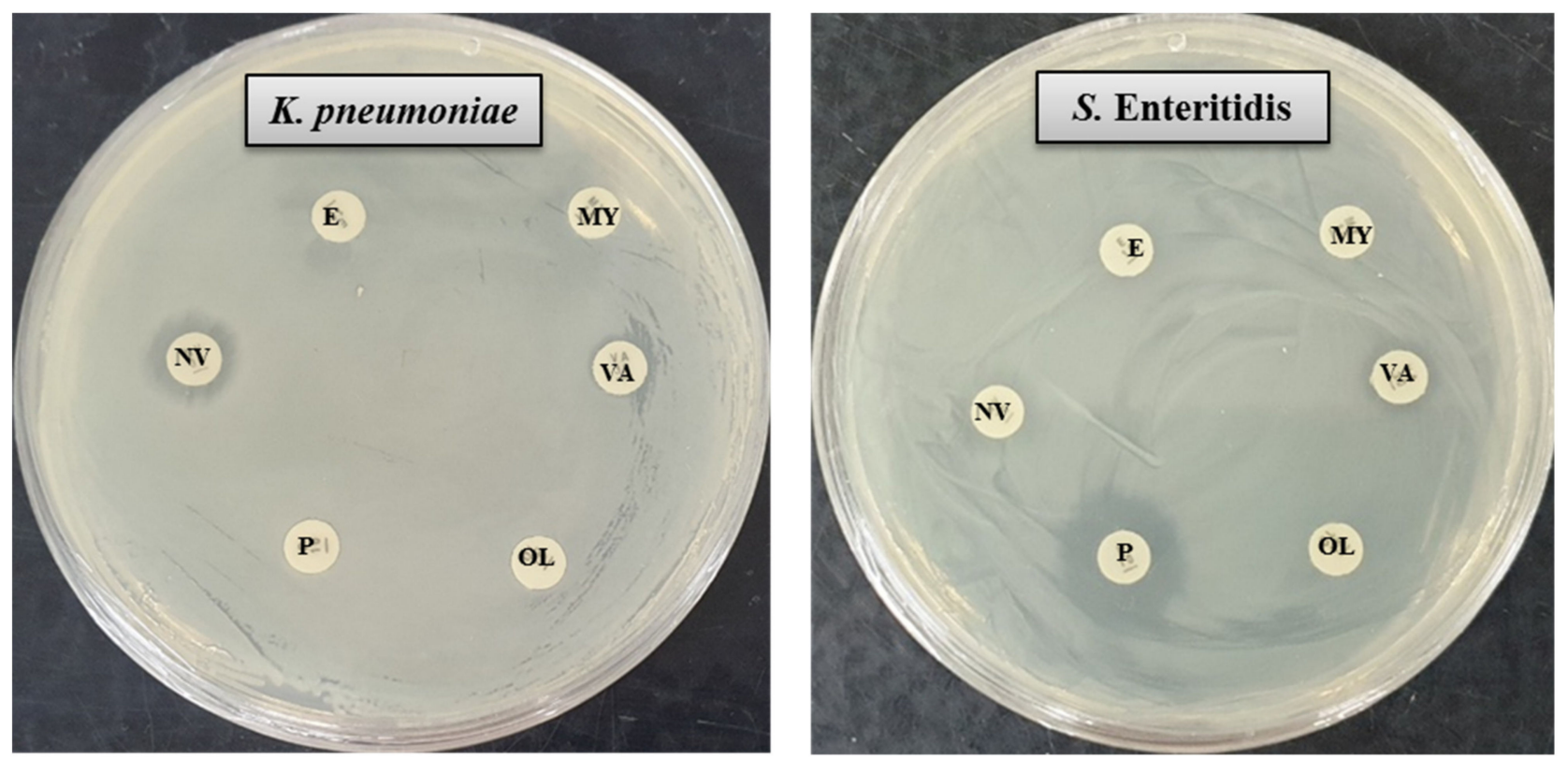

Figure 6. Zones of inhibition of commercial antibiotics against K. pneumoniae and S. Enteritidis. Abbreviations: E (erythromycin, $15 \mu \mathrm{g} / \mathrm{disc}$ ), VA (vancomycin, $30 \mu \mathrm{g} / \mathrm{disc}$ ), MY (lincomycin, $15 \mu \mathrm{g} / \mathrm{disc}$ ), OL (oleandomycin, $15 \mu \mathrm{g} / \mathrm{disc}$ ), $\mathrm{P}$ (penicillin $\mathrm{G}, 10 \mu \mathrm{g} /$ disc), and NV (novobiocin, $30 \mu \mathrm{g} /$ disc). 
Table 2. Antibacterial efficacy of Massilia sp. MAHUQ-52 mediated synthesized AgNPs and certain commercial antibiotics against K. pneumoniae and S. Enteritidis.

\begin{tabular}{|c|c|c|c|c|c|c|c|c|}
\hline \multirow{2}{*}{ Pathogenic Species } & \multicolumn{8}{|c|}{ Zone of Inhibition (mm) } \\
\hline & AgNPs $(30 \mu \mathrm{L})$ & AgNPs $(60 \mu \mathrm{L})$ & Erythromycin & Vancomycin & Oleandomycin & Lincomycin & Penicillin & Novobiocin \\
\hline $\begin{array}{l}\text { Klebsiella pneumoniae } \\
\text { [ATCC 13883] }\end{array}$ & $12.0 \pm 0.7$ & $17.6 \pm 0.5$ & Resistant & Resistant & Resistant & Resistant & Resistant & $9.5 \pm 0.6$ \\
\hline $\begin{array}{l}\text { Salmonella Enteritidis } \\
\text { [ATCC 13076] }\end{array}$ & $11.5 \pm 0.6$ & $16.8 \pm 0.9$ & Resistant & Resistant & Resistant & Resistant & $14.5 \pm 0.8$ & Resistant \\
\hline
\end{tabular}




\section{5. $M I C$ and $M B C$}

The MIC values of synthesized AgNPs against K. pneumoniae and S. Enteritidis were evaluated by a two-fold microdilution assay using 96 well plates. MIC is the lowest concentration of NP that fully inhibits the growth of pathogens. The MICs of Massilia sp. MAHUQ-52 mediated synthesized AgNPs for K. pneumoniae and S. Enteritidis were 12.5 and $25.0 \mu \mathrm{g} / \mathrm{mL}$, respectively (Figure 7). These MIC values were well below other antimicrobial agents including NPs against K. pneumoniae and S. Enteritidis. For example, MIC values of biosynthesized zinc oxide, gold and silver NPs against $K$. pneumoniae were $40,62.5$, and $900 \mu \mathrm{g} / \mathrm{mL}$, respectively $[28,39,40]$. Similarly, the MIC value of zinc oxide NPs against Salmonella spp. was $80 \mu \mathrm{g} / \mathrm{mL}$ [41]. MBC is the minimum concentration of antimicrobial agents that fully kill pathogens. The MBC of Massilia sp. MAHUQ-52 mediated synthesized AgNPs for both K. pneumoniae and S. Enteritidis was $50.0 \mu \mathrm{g} / \mathrm{mL}$ (Figure 8). This MBC value was also well below other antimicrobial agents including NPs against both K. pneumoniae and S. Enteritidis [29,41].

(A)

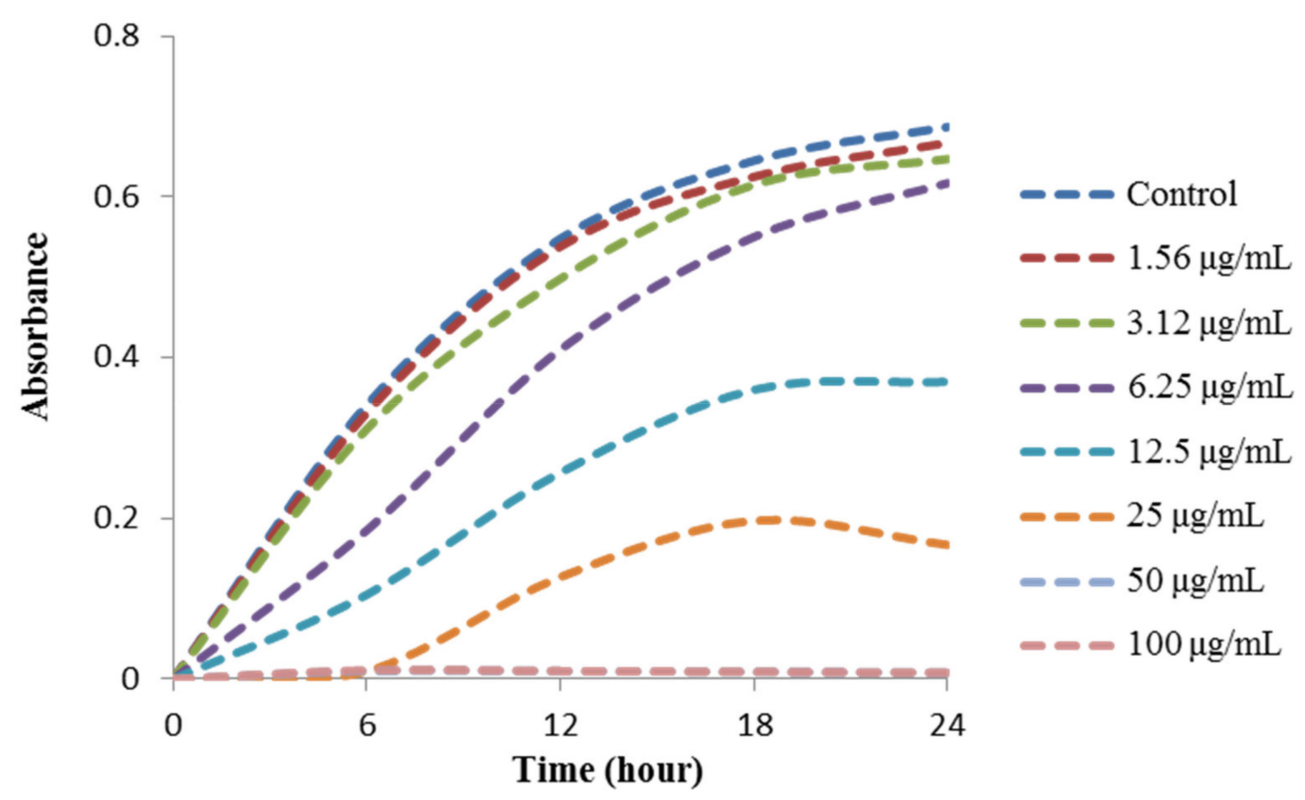

(B)

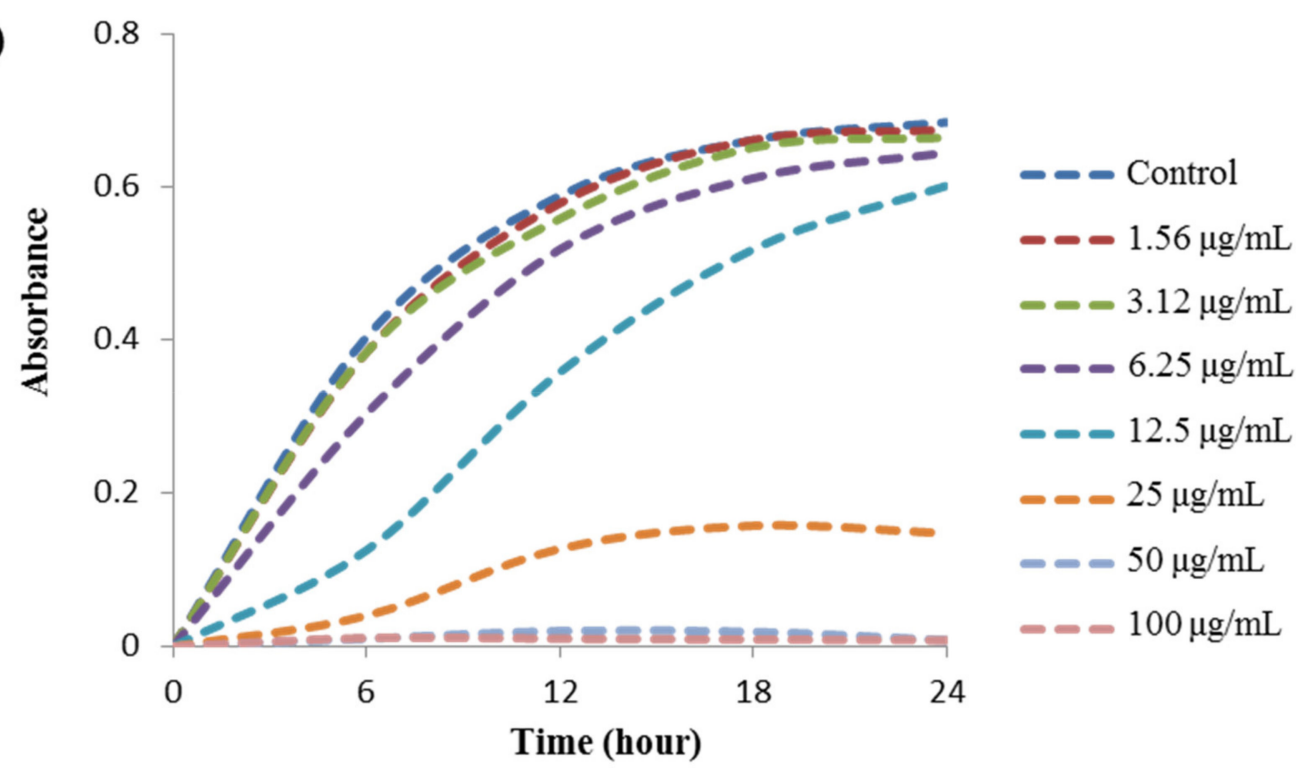

Figure 7. Growth curves of K. pneumoniae (A) and S. Enteritidis (B) cultured in MHB with different concentrations of Massilia sp. MAHUQ-52 mediated synthesized AgNPs to determine MIC. 
(A)

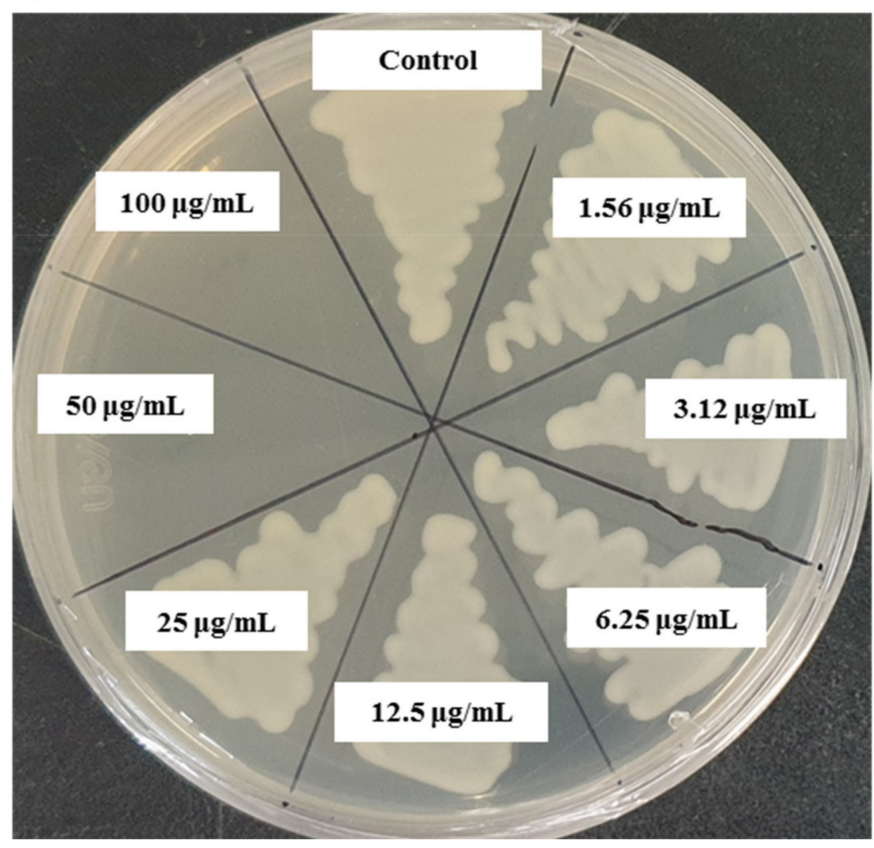

(B)

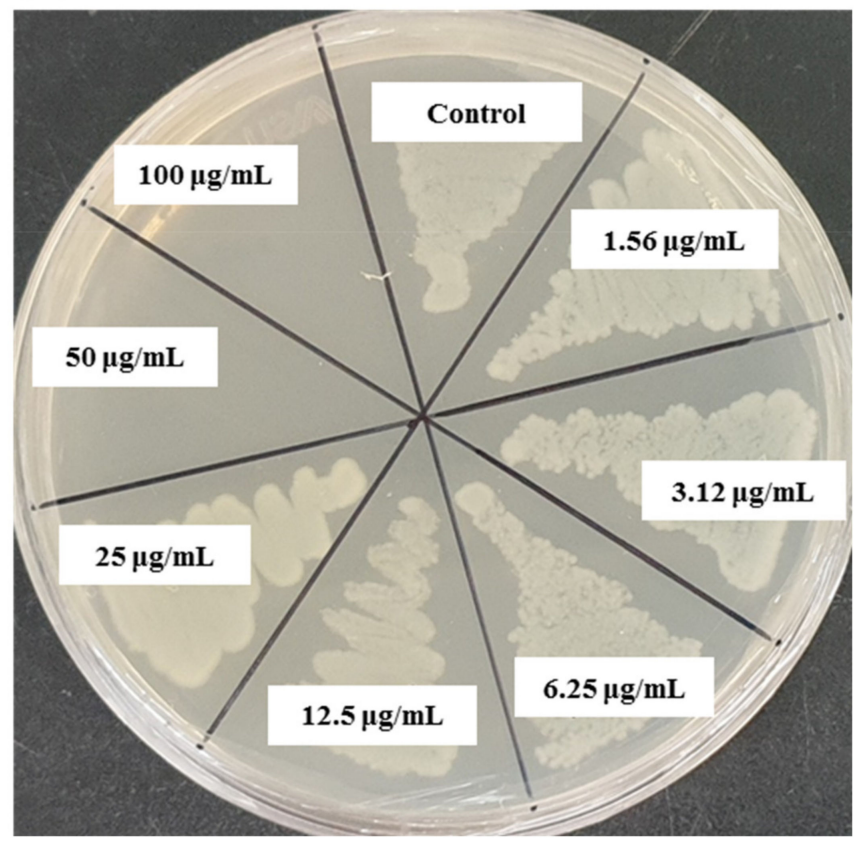

Figure 8. MBC of Massilia sp. MAHUQ-52 mediated synthesized AgNPs against K. pneumoniae (A) and S. Enteritidis (B).

\subsection{Morphological Characterization of Pathogens Incubated with AgNPs}

FE-SEM analysis was performed to investigate the mechanism of the antibacterial activity of Massilia sp. MAHUQ-52 mediated synthesized AgNPs against pathogenic K. pneumoniae and $S$. Enteritidis. The nature and degree of the alteration of morphology and damage of the cellular membrane of both pathogens were seen from FE-SEM images (Figure 9A-D). Untreated K. pneumoniae had an intact and normal shape (Figure 9A). After incubation with synthesized AgNPs, K. pneumoniae showed morphological damage and distortion of the cell wall (Figure 9B). A similar result was found with $S$. Enteritidis. Untreated $S$. Enteritidis had an intact and normal rod shape (Figure 9 C). However, after incubation with synthesized AgNPs, $S$. Enteritidis showed morphological changes with damaged, irregular, abnormal cell walls (Figure 9D). This can be attributed to the oxidative stress due to the formation of reactive oxygen species causing the detachment of the membrane. This ultimately leads to cytoplasm shrinkage and cell wall rupture that both culminate in cell death [42-44]. 
(A)

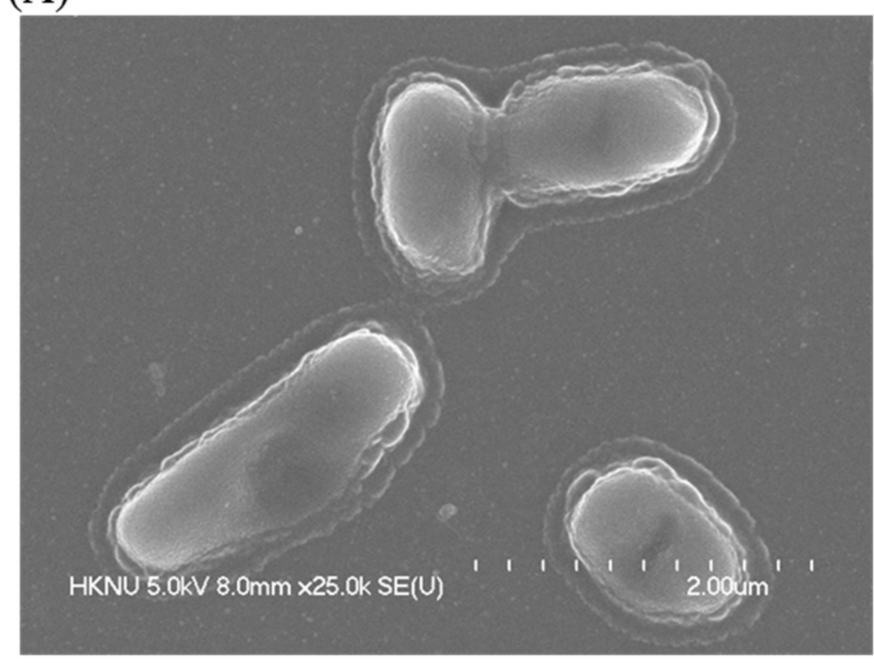

(C)

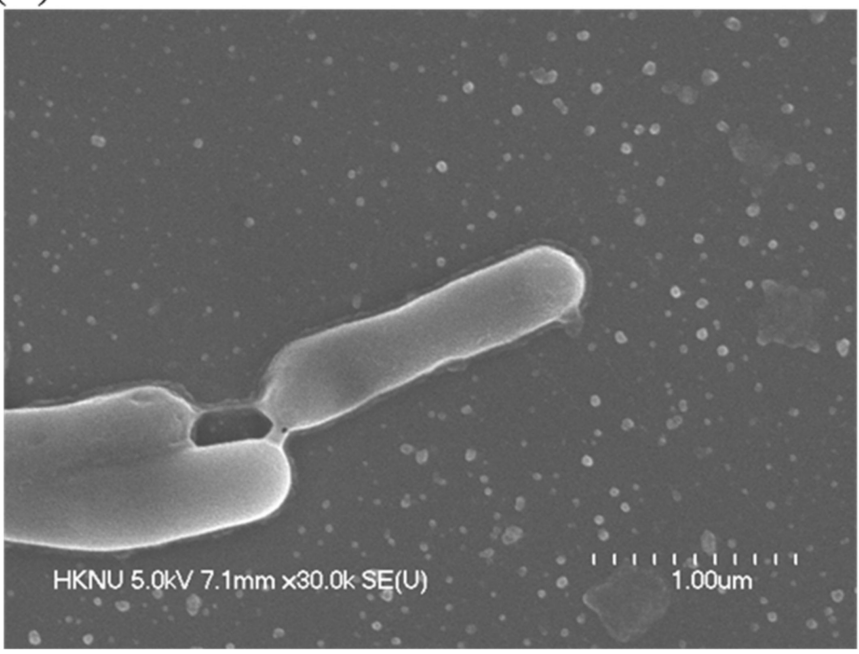

(B)

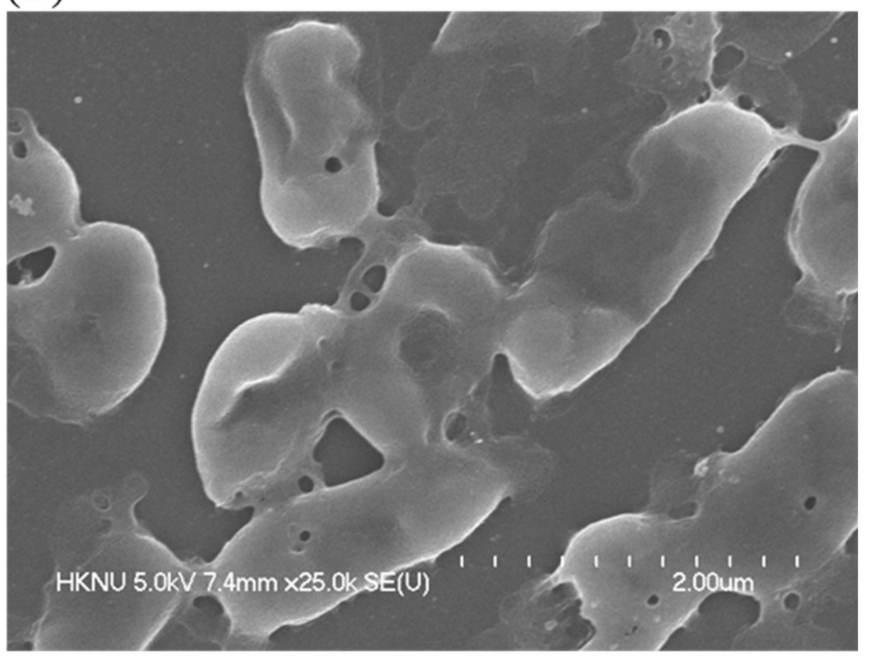

(D)

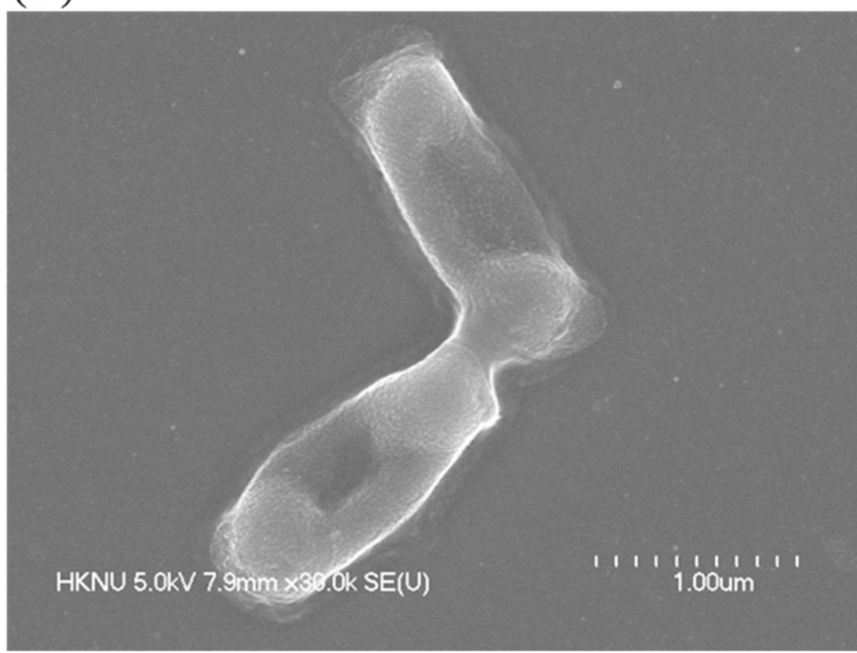

Figure 9. SEM images of normal K. pneumoniae cells (A), $1 \times$ MBC AgNPs treated K. pneumoniae cells (B), normal S. Enteritidis cells $($ C), $1 \times$ MBC AgNPs treated $S$. Enteritidis cells $(\mathbf{D})$.

\section{Materials and Methods}

\subsection{Materials}

Analytical grade silver nitrate $\left(\mathrm{AgNO}_{3}\right)$, ethanol, glutaraldehyde, $\mathrm{MH}$ agar and broth were procured from Sigma-Aldrich (St. Louis, MO, USA). R2A agar and R2A broth were collected from MB-cell (Seoul, South Korea) and standard antibiotic disks were obtained from Oxoid Ltd (Basingstoke, England). The pathogenic strains K. pneumoniae ATCC 13883 and S. Enteritidis ATCC 13076 were obtained from the American Type Culture Collection (ATCC, University Boulevard, Manassas, VA, USA) which were originally isolated from the lungs of pneumonia patients and the gut, respectively.

\subsection{Isolation, Identification and Characterization of AgNPs-Producing Strain MAHUQ-52}

Based on colony morphology, seven bacterial strains were isolated from rhizospheric soil of a banana plant, located in Dighalgram, Magura, Bangladesh using the serial dilution technique [22]. To check the AgNPs synthesis ability, all isolates were cultured separately in $5 \mathrm{~mL}$ R2A broth for $48 \mathrm{~h}$ at $30^{\circ} \mathrm{C}$. Then, the culture supernatant was collected and incubated with $1 \mathrm{mM} \mathrm{AgNO}_{3}$ solution (final concentration) in a shaking incubator for $48 \mathrm{~h}$ at $30^{\circ} \mathrm{C}$. Among all of these isolated strains, only one strain (MAHUQ-52) showed strong AgNPs synthesis ability. Then, the strain (MAHUQ-52) was identified through 16S rRNA gene sequence analysis using bacterial universal primers 27F and 1492R [45]. The 16S rRNA 
gene sequence of strain MAHUQ-52 was submitted to GeneBank, NCBI. The 16S rRNA gene sequences of close relatives were obtained from the EzBioCloud server [46]. The phylogenetic tree was created using the MEGA6 program [47] with the neighbor-joining algorithm to reveal the phylogenetic position of isolated strain MAHUQ-52 [47]. The optimum growth conditions of strain MAHUQ-52 including media, temperature and $\mathrm{pH}$ were examined according to the previous report [22]. The isolated strain MAHUQ-52 was deposited to the Korean Agricultural Culture Collection (KACC).

\subsection{Extracellular Synthesis of AgNPs}

The strain MAHUQ-52 was freshly inoculated in an Erlenmeyer flask containing $100 \mathrm{~mL}$ of R2A broth medium and incubated for $30^{\circ} \mathrm{C}$ in a shaking incubator for $48 \mathrm{~h}$. The culture was centrifuged at $9000 \mathrm{rpm}$ after the incubation period and supernatants were collected for the biosynthesis of AgNPs. A volume of $100 \mu \mathrm{L}$ of $1 \mathrm{M} \mathrm{AgNO}_{3}$ solution $(1 \mathrm{mM}$ final concentration) was added to $100 \mathrm{~mL}$ of culture supernatant in $250 \mathrm{~mL}$ Erlenmeyer flask. The flask was incubated at $30^{\circ} \mathrm{C}$ in a shaking incubator with the dark condition. Primarily, the biosynthesis process was monitored by visual observation through the alteration of color and then confirmed by UV-vis spectral analysis. Finally, the biosynthesized NPs were collected from the reaction mixture by high-speed centrifugation and washed with distilled water. The collected AgNPs were air-dried and used for characterization as well as for antimicrobial application.

\subsection{Characterization of Biosynthesized of AgNPs}

AgNPs were characterized using UV-visible spectroscopy (Optizen POP, Mecasys, Daejeon, South Korea) in the range of 300-800 nm, at regular intervals. For FE-TEM analysis, synthesized AgNPs were dissolved in distilled water, diluted and sonicated. A drop of AgNPs solution was placed on a carbon-coated grid, and water was evaporated. Then, samples were examined (size and shape of AgNPs) with field emission-transmission electron microscopy (FE-TEM) (JEM-2100F, JEOL, Tokyo, Japan) at a voltage acceleration of $200 \mathrm{KV}$. The energy dispersive X-ray (EDX) and selected area diffraction (SAED) were conducted to evaluate the elementary structure of the sample, purity of biosynthesized AgNPs and metallic nature using the detector attached with FE-TEM. To analyze the crystalline nature of the sample, $\mathrm{X}$-ray diffraction (XRD) analysis was performed over the range of 30 to $90^{\circ}(2 \theta)$, operated at $40 \mathrm{KV}$ with $40 \mathrm{~mA}$. Hydrodynamic diameters, polydispersity index (PDI) and zeta potential value (surface charge) of synthesized AgNPs were studied at $23{ }^{\circ} \mathrm{C}$ using a Malvern Zetasizer Nano ZS90 (Malvern Instruments, Worcestershire, UK) according to the previous description [23]. The surface chemistry of the sample to determine the functional groups associated with synthesized AgNPs was investigated using FT-IR spectroscopy over the range of $4000-500 \mathrm{~cm}^{-1}$. For FT-IR analysis, air-dried green synthesized AgNPs and freeze-dried culture supernatant in powder form were used.

\subsection{Antimicrobial Activity of Biosynthesized AgNPs}

The antimicrobial activity of the biosynthesized AgNPs against pathogenic K. pneumoniae and $S$. Enteritidis was investigated by the disk diffusion method (zone of inhibition, ZOI) [27]. Briefly, the pure colonies of K. pneumoniae and S. Enteritidis were grown in MHB medium for overnight at $37^{\circ} \mathrm{C}(180 \mathrm{rpm})$. A volume of $100 \mu \mathrm{L}$ of overnight culture fresh pathogens was spread uniformly on the $\mathrm{MH}$ agar and sterile paper discs were placed on the media. Then, 30 and $60 \mu \mathrm{L}$ Massilia sp. MAHUQ-52 mediated synthesized AgNPs solution $(1 \mathrm{mg} / \mathrm{mL}$, dissolved in distilled water) was poured on the paper discs. Similarly, six standard antibiotics (erythromycin, $15 \mu \mathrm{g} /$ disc; vancomycin, $30 \mu \mathrm{g} / \mathrm{disc}$; penicillin $\mathrm{G}$, $10 \mu \mathrm{g} / \mathrm{disc}$; novobiocin, $30 \mu \mathrm{g} / \mathrm{disc}$; lincomycin, $15 \mu \mathrm{g} / \mathrm{disc}$ and oleandomycin, $15 \mu \mathrm{g} / \mathrm{disc}$ were used as controls against both K. pneumoniae and $S$. Enteritidis. All plates were incubated at $37^{\circ} \mathrm{C}$ for $24 \mathrm{~h}$ to check the zone of inhibition (ZOI). Upon the end of incubation, the plates were observed for the presence of ZOI surrounding each well, which was calculated and expressed in millimeters ( $\mathrm{mm})$. 


\subsection{MIC and MBC}

The broth microdilution method was used to determine the MIC of synthesized AgNPs against K. pneumoniae and S. Enteritidis. Shortly, both pathogenic bacteria were grown overnight in $\mathrm{MH}$ broth, and the turbidity was adjusted around $1 \times 10^{6} \mathrm{CFU} / \mathrm{mL}$. Then, $100 \mu \mathrm{L}$ of each pathogenic bacteria was added into 96-well plates and equal volume $(100 \mu \mathrm{L})$ of Massilia sp. MAHUQ-52 mediated synthesized AgNPs solution with various concentration $(200,100,50,25,12.5,6.2,3.1$ and $1.5 \mu \mathrm{g} / \mathrm{mL})$ was added. As a control, only MH broth was used instead of AgNPs solution. Then, the 96 well plates were incubated in a shaking incubator for $24 \mathrm{~h}$ at $37^{\circ} \mathrm{C}$. Every $3 \mathrm{~h}$ of interval, absorbance $(600 \mathrm{~nm})$ was taken using an ELISA plate reader (LabTech 4000) (BMG LABTECH, Ortenberg, Germany). The MBC of synthesized AgNPs against K. pneumoniae and S. Enteritidis was determined by streaking $10 \mu \mathrm{L}$ of each suspension from 96 well plates and incubating for $24 \mathrm{~h}$ at $37^{\circ} \mathrm{C}$. Upon the end of incubation, the minimum concentration of NPs that fully killed the pathogens on MHA plates was recorded as the MBC.

\subsection{Morphological Characterization of Pathogens Incubated with AgNPs}

Bacterial strains of K. pneumoniae and S. Enteritidis (log-phase cells, approximately $1 \times 10^{7} \mathrm{CFU} / \mathrm{mL}$ ) were each incubated with and without AgNPs (at MBC concentration) for $12 \mathrm{~h}$ at $37^{\circ} \mathrm{C}$. After the incubation period, samples were collected from both cultures and processed for FE-SEM analysis according to the previous description [17]. Briefly, the overnight-treated cells were centrifuged at $8000 \mathrm{rpm}$ for $5 \mathrm{~min}$, and the supernatant was poured out. Then, the pellets were washed by PBS (pH 7.0) and fixed at room temperature with $2.5 \%$ glutaraldehyde for $4 \mathrm{~h}$. Subsequently, the cells were again washed several times by PBS and serially dehydrated with different concentrations of ethanol $(30,50,70,90,95$, and $100 \%$ ) in $10 \mathrm{~min}$ intervals at room temperature. Finally, the dehydrated cells were dried by a desiccator and the samples were coated with gold for morphological and structural evaluation by FE-SEM (JSM-7100F, JEOL, Japan) [48].

\section{Conclusions}

This study is an attempt to control multi-drug resistant pathogenic K. pneumoniae and S. Enteritidis by the facile and eco-friendly synthesized AgNPs. The convenient extracellular methodology was used for the rapid synthesis of AgNPs using Massilia sp. MAHUQ-52. FT-IR analysis confirmed the capping of the AgNPs by the biomolecules of the culture supernatant. MAHUQ-52 mediated synthesized AgNPs exhibited promising antimicrobial activity against both K. pneumoniae and S. Enteritidis. AgNPs showed ZOI of $17.6 \pm 0.5$ and $16.8 \pm 0.9 \mathrm{~mm}$ against K. pneumoniae and $S$. Enteritidis, respectively. The MIC values of AgNPs against K. pneumoniae and S. Enteritidis were 12.5 and $25.0 \mu \mathrm{g} / \mathrm{mL}$, respectively. The MBC was $50 \mu \mathrm{g} / \mathrm{mL}$ for both pathogens. Moreover, the FE-SEM analysis of AgNPs treated cells showed the morphological changes as damaged, irregular, abnormal cell walls. These changes ultimately lead to cytoplasm shrinkage and cell wall rupture that culminated in cell death. Finally, the isolated strain Massilia sp. MAHUQ-52 can be useful for the facile and eco-friendly synthesis of AgNPs and Massilia sp. MAHUQ-52 mediated synthesized AgNPs can be utilized as an antimicrobial agent against drugresistant pathogens to overcome microbial threats.

Supplementary Materials: Figure S1: Effect of incubation time on the green synthesis of AgNPs using Massilia sp. MAHUQ-52 was checked on the basis of UV-vis spectral analysis after $24 \mathrm{~h}$, $48 \mathrm{~h}$ and $72 \mathrm{~h}$ of incubation at $30^{\circ} \mathrm{C}$ with $1 \mathrm{mM}$ concentration of AgNO3., Figure S2: Particles size distribution of Massilia sp. MAHUQ-52 mediated synthesized AgNPs according to intensity (A), number (B) and volume (C), and Figure S3: Zeta potential distribution showed the negative zeta potential value.

Author Contributions: M.A.H. conceived the original screening and research plans and wrote the article. M.A.H. and S.A. performed all of the experiments. All authors have read and agreed to the published version of the manuscript. 
Funding: This study was performed with the support of the National Research Foundation (NRF) of Korea grant (project no. NRF-2018R1C1B5041386, grant recipient: Md. Amdadul Huq) funded by Korean government, Republic of Korea.

Institutional Review Board Statement: Not applicable.

Informed Consent Statement: Not applicable.

Data Availability Statement: Data are available on request from the corresponding authors.

Conflicts of Interest: The authors declare that they have no conflict of interest.

Sample Availability: Not available.

\section{References}

1. Zhang, X.F.; Liu, Z.G.; Shen, W.; Gurunathan, S. Silver nanoparticles: Synthesis, characterization, properties, applications, and therapeutic approaches. Int. J. Mol. Sci. 2016, 17, 1534. [CrossRef] [PubMed]

2. Jeevanandam, J.; Barhoum, A.; Chan, Y.S.; Dufresne, A.; Danquah, M.K. Review on nanoparticles and nanostructured materials: History, sources, toxicity and regulations. Beilstein J. Nanotechnol. 2018, 9, 1050-1074. [CrossRef] [PubMed]

3. Khan, I.; Saeed, K.; Khan, I. Nanoparticles: Properties, applications and toxicities. Arab. J. Chem. 2019, 12, 908-931. [CrossRef]

4. Huq, M.A. Green Synthesis of Silver Nanoparticles Using Pseudoduganella eburnean MAHUQ-39 and Their Antimicrobial Mechanisms Investigation against Drug Resistant Human Pathogens. Int. J. Mol. Sci. 2020, 21, 1510. [CrossRef] [PubMed]

5. Kedi, P.B.E.; Meva, F.E.; Kotsedi, L. Eco-friendly synthesis, characterization, in vitro and in vivo anti-inflammatory activity of silver nanoparticle-mediated Selaginella myosurus aqueous extract. Int. J. Nanomed. 2018, 13, 8537-8548. [CrossRef]

6. El-Naggar, N.E.; Hussein, M.H.; El-Sawah, A.A. Bio-fabrication of silver nanoparticles by phycocyanin, characterization, in vitro anticancer activity against breast cancer cell line and in vivo cytotoxicity. Sci. Rep. 2017, 7, 10844. [CrossRef] [PubMed]

7. Fouda, A.; Abdel-Maksoud, G.; Abdel-Rahman, M.A.; Salem, S.S.; Hassan, S.E.D.; El-Sadany, M.A.H. Eco-friendly approach utilizing green synthesized nanoparticles for paper conservation against microbes involved in biodeterioration of archaeological manuscript. Int. Biodeterior. Biodegrad. 2019, 142, 160-169. [CrossRef]

8. Fouda, A.; Abdel-Maksoud, G.; Abdel-Rahman, M.A.; Eid, A.M.; Barghoth, M.G.; El-Sadany, M.A.H. Monitoring the effect of biosynthesized nanoparticles against biodeterioration of cellulose-based materials by Aspergillus niger. Cellulose 2019, 26, 6583-6597. [CrossRef]

9. Cheon, J.Y.; Kim, S.J.; Rhee, Y.H.; Kwon, O.H.; Park, W.H. Shape-dependent antimicrobial activities of silver nanoparticles. Int. J. Nanomed. 2019, 14, 2773-2780. [CrossRef]

10. Burdușel, A.C.; Gherasim, O.; Grumezescu, A.M.; Mogoanta, L.; Ficai, A.; Andronescu, E. Biomedical Applications of Silver Nanoparticles: An Up-to-Date Overview. Nanomaterials 2018, 8, 681. [CrossRef]

11. Siddiqi, K.S.; Husen, A.; Rao, R.A.K. A review on biosynthesis of silver nanoparticles and their biocidal properties. J. Nanobiotechnol. 2018, 16, 14. [CrossRef]

12. Akter, S.; Huq, M.A. Biologically rapid synthesis of silver nanoparticles by Sphingobium sp. MAH- $11^{\mathrm{T}}$ and their antibacterial activity and mechanisms investigation against drug-resistant pathogenic microbes. Artif. Cells Nanomed. Biotechnol. 2020, 48, 672-682. [CrossRef]

13. Huq, M.A. Biogenic Silver Nanoparticles Synthesized by Lysinibacillus xylanilyticus MAHUQ-40 to Control Antibiotic-Resistant Human Pathogens Vibrio parahaemolyticus and Salmonella Typhimurium. Front. Bioeng. Biotechnol. 2020, 8, 1407. [CrossRef]

14. Salem, S.S.; Fouda, A. Green synthesis of metallic nanoparticles and their prospective biotechnological applications: An overview. Biol. Trace Elem. Res. 2020, 199, 344-370. [CrossRef]

15. Rafique, M.; Sadaf, I.; Rafique, M.S.; Tahir, M.B. A review on green synthesis of silver nanoparticles and their applications. Artif. Cells Nanomed. Biotechnol. 2017, 45, 1272-1291. [CrossRef] [PubMed]

16. Shantkriti, S.; Rani, P. Biological synthesis of copper nanoparticles using Pseudomonas fluorescens. Int. J. Curr. Microbiol. Appl. Sci. 2014, 3, 374-383.

17. Huq, M.A.; Akter, S. Bacterial Mediated Rapid and Facile Synthesis of Silver Nanoparticles and Their Antimicrobial Efficacy against Pathogenic Microorganisms. Materials 2021, 14, 2615. [CrossRef]

18. Chowdhury, P.; Roy, B.; Mukherjee, N.; Mukherjee, S.; Joardar, N.; Mondal, M.K.; Roy, D.; Sinha Babu, S.P. Chitosan biopolymer functionalized gold nanoparticles with controlled cytotoxicity and improved antifilarial efficacy. Adv. Compos. Hybrid Mater. 2018, 1, 577-590. [CrossRef]

19. Khoshnamvand, M.; Ashtiani, S.; Huo, C.; Saeb, S.P.; Liu, J. Use of Alcea rosea leaf extract for biomimetic synthesis of gold nanoparticles with innate free radical scavenging and catalytic activities. J. Mol. Struct. 2019, 1179, 749-755. [CrossRef]

20. Varghese, R.J.; Zikalala, N.; Sakho, E.H.M.; Oluwafemi, O.S. Green synthesis protocol on metal oxide nanoparticles using plant extracts. Colloid. Met. Oxide Nanopart. 2020, 67-82.

21. Vaidyanathan, R.; Gopalram, S.; Kalishwaralal, K.; Deepak, V.; Pandian, S.R.; Gurunathan, S. Enhanced silver nanoparticle synthesis by optimization of nitrate reductase activity. Colloids Surf. B. Biointerfaces 2010, 75, 335-341. [CrossRef] 
22. Huq, M.A. Paenibacillus anseongense sp. nov. a Silver Nanoparticle Producing Bacterium Isolated from Rhizospheric Soil. Curr. Microbiol. 2020, 77, 2023-2030. [CrossRef]

23. Du, J.; Sing, H.; Yi, T.H. Biosynthesis of silver nanoparticles by Novosphingobium sp. THG-C3 and their antimicrobial potential. Artif. Cells. Nanomed. Biotechnol. 2017, 45, 211-217. [CrossRef]

24. Huq, M.A. Microvirga rosea sp. nov.: A nanoparticle producing bacterium isolated from soil of rose garden. Arch. Microbiol. 2018, 200, 1439-1445. [CrossRef]

25. Singh, H.; Du, J.; Singh, P.; Yi, T.H. Extracellular synthesis of silver nanoparticles by Pseudomonas sp. THG-LS1.4 and their antimicrobial application. J. Pharm. Anal. 2018, 8, 258-264. [CrossRef]

26. Akter, S.; Lee, S.-Y.; Siddiqi, M.Z.; Balusamy, S.R.; Ashrafudoulla, M.; Rupa, E.J.; Huq, M.A. Ecofriendly synthesis of silver nanoparticles by Terrabacter humi sp. nov. and their antibacterial application against antibiotic-resistant pathogens. Int. J. Mol. Sci. 2020, 21, 9746. [CrossRef]

27. Singh, P.; Singh, H.; Kim, Y.J. Extracellular synthesis of silver and gold nanoparticles by Sporosarcina koreensis DC4 and their biological applications. Enzym. Microb. Technol. 2016, 86, 75-83. [CrossRef] [PubMed]

28. Iqbal, J.; Ahemad, M. Recent advances in bacteria-assisted phytoremediation of heavy metals from contaminated soil. Adv. Biodegrad. Bioremediat. Ind. Waste 2015, 415-438.

29. Hamida, R.M.; Ali, M.A.; Goda, D.A.; Khalilad, M.I.; Redhwan, A. Cytotoxic effect of green silver nanoparticles against ampicillin-resistant Klebsiella pneumoniae. RSC Adv. 2020, 10, 21136-21146. [CrossRef]

30. Afshari, A.; Baratpour, A.; Khanzade, S.; Jamshidi, A. Salmonella Enteritidis and Salmonella Typhimorium identification in poultry carcasses. Iran. J. Microbiol. 2018, 10, 45-50.

31. Gallego, V.; Sa'nchez-Porro, C.; Garc1'a, M.T.; Ventosa, A. Massilia aurea sp. nov., isolated from drinking water. Int. J. Syst. Evol. Microbiol. 2006, 56, 2449-2453. [CrossRef] [PubMed]

32. Yang, E.; Zhao, M.; Li, S.; Wang, Y.; Sun, L.; Liu, J.; Wang, W. Massilia atriviolacea sp. nov., a dark purple-pigmented bacterium isolated from soil. Int. J. Syst. Evol. Microbiol. 2019, 69, 2135-2141. [CrossRef] [PubMed]

33. Ganesh-Babu, M.M.; Gunasekaran, P. Production and structural characterization of crystalline silver nanoparticles from Bacillus cereus isolate. Colloids Surf. B Biointerfaces 2009, 74, 191-195. [CrossRef] [PubMed]

34. Singh, P.; Pandit, S.; Mokkapati, S.; Garnæs, J.; Mijakovic, I. A Sustainable Approach for the Green Synthesis of Silver Nanoparticles from Solibacillus isronensis sp. and Their Application in Biofilm Inhibition. Molecules 2020, 25, 2783. [CrossRef]

35. Mott, D.; Galkowski, J.; Wang, L.; Luo, J.; Zhong, C.J. Synthesis of size-controlled and shaped copper nanoparticles. Langmuir 2007, 23, 5740-5745. [CrossRef]

36. Brause, R.; Moeltgen, H.; Kleinermanns, K. Characterization of laser-ablated and chemically reduced silver colloids in aqueous solution by UV/VIS spectroscopy and STM/SEM microscopy. Appl. Phys. B 2002, 75, 711-716. [CrossRef]

37. Krishnaraj, C.; Jagan, E.; Rajasekar, S.; Selvakumar, P.; Kalaichelvan, P.; Mohan, N. Synthesis of silver nanoparticles using Acalypha indica leaf extracts and its antibacterial activity against water borne pathogens. Colloids Surf. B Biointerfaces 2010, 76, 50-56. [CrossRef]

38. Singh, P.; Pandit, S.; Jers, C.; Abhayraj, S.; Garnæs, J.; Mijakovic, I. Silver nanoparticles produced from Cedecea sp. exhibit antibiofilm activity and remarkable stability. Sci. Rep. 2021, 11, 12619. [CrossRef]

39. Reddy, L.S.; Nisha, M.M.; Joice, M.; Shilpa, P.N. Antimicrobial activity of zinc oxide (ZnO) nanoparticle against Klebsiella pneumoniae. Pharm. Biol. 2014, 52, 1388-1397. [CrossRef]

40. Fanoro, O.T.; Parani, S.; Maluleke, R.; Lebepe, T.C.; Varghese, J.R.; Mavumengwana, V.; Oluwafemi, O.L. Facile Green, RoomTemperature Synthesis of Gold Nanoparticles Using Combretum erythrophyllum Leaf Extract: Antibacterial and Cell Viability Studies against Normal and Cancerous Cells. Antibiotics 2021, 10, 893. [CrossRef]

41. Yusof, H.M.; Rahman, N.A.; Mohamad, R.; Zaidan, U.H.; Samsudin, A.A. Antibacterial Potential of Biosynthesized Zinc Oxide Nanoparticles against Poultry-Associated Foodborne Pathogens: An In Vitro Study. Animals 2021, 11, 2093. [CrossRef]

42. Ansari, M.A.; Kalam, A.; Al-Sehemi, A.G.; Alomary, M.N.; AlYahya, S.; Aziz, M.K.; Srivastava, S.; Alghamdi, S.; Akhtar, S.; Almalki, H.D.; et al. Counteraction of Biofilm Formation and Antimicrobial Potential of Terminalia catappa Functionalized Silver Nanoparticles against Candida albicans and Multidrug-Resistant Gram-Negative and Gram-Positive Bacteria. Antibiotics 2021, 10, 725. [CrossRef] [PubMed]

43. Hu, X.; Xu, X.; Fu, F.; Yang, B.; Zhang, J.; Zhang, Y.; Binte Touhid, S.S.; Liu, L.; Dong, Y.; Liu, X.; et al. Synthesis of bimetallic silver-gold nanoparticle composites using a cellulose dope: Tunable nanostructure and its biological activity. Carbohydr. Polym. 2020, 248, 116777. [CrossRef] [PubMed]

44. Fanoro, O.T.; Oluwafemi, O.S. Bactericidal antibacterial mechanism of plant synthesized silver, gold and bimetallic nanoparticles. Pharmaceutics 2020, 12, 1044. [CrossRef] [PubMed]

45. Weisburg, W.G.; Barns, S.M.; Pelletier, D.A.; Lane, D.J. $16 \mathrm{~S}$ ribosomal DNA amplification for phylogenetic study. J. Bacteriol. 1991, 173, 697-703. [CrossRef]

46. Yoon, S.H.; Ha, S.M.; Kwon, S.; Lim, J.; Kim, Y. Introducing EzBioCloud: A taxonomically united database of 16S rRNA gene sequences and whole-genome assemblies. Int. J Syst. Evol. Microbiol. 2017, 67, 1613-1617. [CrossRef] [PubMed]

47. Tamura, K.; Stecher, G.; Peterson, D.; Filipski, A.; Kumar, S. MEGA6: Molecular evolutionary genetics analysis version 6.0. Mol. Biol. Evol. 2013, 30, 2725-2729. [CrossRef] [PubMed]

48. Ansari, M.A.; Baykal, A.; Asiri, S. Synthesis and characterization of antibacterial activity of spinel chromium-substituted copper ferrite nanoparticles for biomedical application. J. Inorg. Organomet. Polym. Mater. 2018, 28, 2316-2327. [CrossRef] 